\title{
PENGARUH ATMOSFIR TOKO DAN KESESUAIAN HARGA TERHADAP KEPUTUSAN PEMBELIAN KONSUMEN PUNCAK DEPARTEMENT STORE BENGKULU
}

\author{
Tito Irwanto 1), Herry Novrianda 2), Aji Purnomo \\ 1) Program Studi Manajemen Fakultas Ekonomi Universitas Dehasen Bengkulu \\ 2) Program Studi Manajemen Fakultas Ekonomi Universitas Terbuka Bengkulu \\ tito.irwanto22@gmail.com ; herry.novrianda@ecampus.ut.ac.id ; $\underline{\text { AjiPurnomo171996@gmail.com }}$
}

\begin{abstract}
ABSTRAK
Tito Irwanto, Herry Novrianda, Aji Purnomo; Penelitian ini bertujuan untuk mengetahui pengaruh positif antara atmosfir dan kesesuaian harga terhadap keputusan pembelian pada konsumen yang berkunjung kePuncak Departement Store Kota Bengkulu.Jumlah sampel 100 pengunjung dengan menggunakan metode regresi linier berganda. Metode analisa yang digunakan dalam penelitian ini adalah regresi linier berganda.Hasil dari penelitian ini adalah terdapat pengaruh atmosfir terhadap keputusan pembelian pada konsumen yang berkunjung ke Puncak Departement Store Kota Bengkulu, hal ini terbukti pada nilai thitungstabel sebesar 12,839> 1,66 dan terdapat pengaruh kesesuaian harga terhadap keputusan pembelian pada konsumen yang berkunjung ke Puncak Departement Store Kota Bengkulu, hal ini terbukti pada nilai thitung $t_{t a b e l}$ kesesuaian harga sebesar 2,267> 1,66. Berdasarkan perbandingan nilai $\mathrm{F}_{\text {hitung }}$ dengan $\mathrm{F}_{\text {tabel }}$ diketahui nilai $\mathrm{F}_{\text {hitung }}$ lebih besar dari pada nilai $\mathrm{F}$ tabel yaitu 114,992> 3,09 maka hipotesis diterima, artinya ada pengaruh simultan antara atmosfir dan kesesuaian harga terhadap keputusan pembelian pada konsumen di Puncak Departement Store Kota Bengkulu.
\end{abstract}

\begin{abstract}
Tito Irwanto, Herry Novrianda, Aji Purnomo; This study aims to determine the positive effect between atmosphere and price suitability on purchasing decisions for consumers visiting the Peak of the Bengkulu City Department Store. The number of samples is 100 visitors using the multiple linear regression method. The method of analysis used in this study is multiple linear regression. The results of this study are that there is an influence of the atmosphere on purchasing decisions on consumers visiting the Peak of the Bengkulu City Department Store, this is evident in the value of tcount>ttable of 12.839>1.66 and there is an influence of price suitability on purchasing decisions on consumers visiting the Peak Department of Store of the City of Bengkulu, this is evident in the value of $t>t$ table of conformity of the price of 2.267> 1.66. Based on the comparison of the value of Fcount with Ftable, it is known that the Fcount value is greater than the Ftable value that is 114.992> 3.09, then the hypothesis is accepted, meaning that there is a simultaneous influence between the atmosphere and the suitability of prices towards purchasing decisions on consumers at the Top of the Department Store Store in Bengkulu City.
\end{abstract}

Keywords: Atmosphere, Price Match, and Purchase Decision

\section{LATAR BELAKANG}

Kondisi persaingan dalam dunia bisnis menuntut setiap pengusaha untuk mampu bersaing dan bertahan melawan pesaing.Banyaknya perusahaan yang berlomba untuk mendapatkan konsumen menjadikan kondisi kompetisi antar perusahaan berlangsung semakin ketat.Persaingan yang sangat ketat menuntut para pengusaha untuk dapat menentukan yang tepat dalam berkompetisi.Hal tersebut membuat pengusaha toko atau swalayan harus berupaya untuk memahami kebutuhan, keinginan, danpermintaan pasar sasaran. Salah satu cara untuk memenangkan persaingan adalah dengan membuat sesuatu yang berbeda.

Membuat sesuatu yang berbeda bisa diartikan tampilan yang berbeda ataupun harga yang ditawarkan berbeda dari toko atau swalayan lainnya sehingga dapat terlihat atmosfir atau daya tarik dari toko atau swalayan tersebut.Adapun daya tarik lainnya bisa berupa kesesuaian harga yang ditawarkan kepada calon konsumen sehingga calon konsumen dapat tertarik untuk membeli produk yang ditawarkan. Dalam penilaian atau tanggapan konsumen terhadap atmosfir toko akan mempengaruhi pembelian konsumen, salah satu yang menjadi pertimbangan dalam pengambilan keputusan pembelian adalah atmosfir tokoyang menarik dan harga yang sesuai dengan kualitas produk.

Puncak Departement Store memiliki konsep sedikit berbeda dari toko lainnya yaitu memiliki beberapa departement seperti departemen busana, peralatan rumah tangga, sampai ke swalayan. Selain itu Toko Puncak Departement Store memiliki pencahayaan, layanan, musik, layout, dan kenyamanan 
terhadap minat beli konsumen yang membuat konsumen tertarik untuk berbelanja disana. Selain itu Puncak Departement Store menjual semua kebutuhan rumah tangga, mulai dari kebutuhan dapur, pakaian/busana, perabot rumah tangga, hand phone dan lain-lain. Adapun harga yang ditawarkan tidak kalah bersaing dengan harga ditoko atau swalayan lainnya..

\section{LANDASAN TEORI \\ Manajemen Pemasaran}

Menurut Assauri (2013:12) pengertian manajemen pemasaran adalah merupakan kegiatan penganalisisan, perencanaan, pelaksanaan, dan pengendalian program-program yang dibuat untuk membentuk, membangun, dan memelihara keuntungan dari pertukaran melalui sasaran pasar guna mencapai tujuan organisasi (perusahaan) dalam jangka panjang.

Pengertian lainnya dikemukakan oleh Armstrong dan Kotler (2012:29) yang menyatakan bahwa manajemen pemasaran adalah serangkaian proses yang dilakukan oleh perusahaan untuk menciptakan suatu nilai bagi para pelanggan dan membangun hubungan yang kuat dengan mereka agar tercipta suatu nilai dari para pelanggan tersebut.

\section{Bauran Pemasaran}

Menurut Kotler dan Keller (2012:47) dalam bukunya Marketing Management mendefinisikan bauran pemasaran sebagai seperangkat alat pemasaran perusahaan menggunakan untuk mengejar tujuan pemasarannya di pasar sasaran.

1. Produk (Product)

Suatu yang dapat ditawarkan ke pasar untuk mendapatkan perhatian, agar produk yang dijual mau dibeli, digunakan atau dikonsumsi yang dapat memenuhi suatu keinginan atau kebutuhan dari konsumen.

2. Harga (Price)

Sejumlah nilai yang ditukarkan konsumen dengan manfaat dari memiliki atau menggunakan produk atau jasa yang nilainya ditetapkan oleh pembelian dan penjual melalui tawar menawar, atau ditetapkan oleh penjual untuk satu harga yang sama terhadap semua pembelian.

3. Tempat (Place)

Tempat diasosiasikan sebagai saluran distribusi yang ditujukan untuk mencapai taget konsumen.Sistem distribusi ini mencakup lokasi, transportasi, pergudangan, dan sebagainya.

4. Promosi (Promotion)

Sebagai salah satu cara pemasaran untuk mengkomunikasikan dan menjual suatu produk kepada konsumen yang berpotensi.

\section{Strategi Pemasaran}

Strategi pemasaran merupakan suatu proses strategi pengembangan pemasaran yang harus memperhatikan perubahan situasi dan untuk mencapai kepuasan pelanggan. Strategi pemasaran lebih difokuskan pada pelaksanaan strategi itu sendiri dari pada kegiatan peningkatan penjualan dimana strategi ini di utamakan konsumen/pelanggan dalam mempengaruhi pelanggan diperlukan strategi pemasaran yang terkoordinasi yang menghubungkan kegiatan perusahaan dengan situasi yang ada, Sutisna (2012:5).

\section{Atmosfir Toko}

Store atmosphere merupakan salah satu unsur dari retailing mix yang harus diperhatikan dalam membangun bisnis ritel. Levy dan Weitz (2009:530) menyatakan Atmospherics refers to the design of an environment through visual communications, lighting, colors, music, and scent that stimulate customers perceptual and emotional responses and ultimately affect their purchase behavior. Menurut definisi tersebut dapat dapat disimpulkan bahwa atmosfir mengacu pada perancangan suasana pada komunikasi visual, pencahayaan, warna, musik, dan aroma yang menstimuli persepsi dan respon emosional konsumen serta mempengaruhi perilaku mereka.

Menurut Karmela dan Junaedi (2009:102) menyatakan atmosfir toko yang baik dan menyenangkan juga akan dapat menjaga dan mendorong citra perusahaan. Citra toko yang baik dapat menjamin kelangsungan hidup perusahaan untuk bertahan terhadap persaingan dalam membentuk pelanggan yang loyal, sama halnya dengan atmosfir toko dapat membuat konsumen untuk lebih loyal. 


\section{Kesesuaian Harga}

Harga adalah jumlah yangditagihkan atas suatu produk atau jasa.Lebih luas lagi, harga adalah jumlah semuanilai yang diberikan oleh pelanggan untuk mendapatkan keuntungan dari memilikiatau menggunakan suatu produk atau jasa.Kotler dan Armstrong (dalam Jaya 2018:2897).Strategi penyesuaian harga perusahaan biasanya menyesuaikan harga dasar mereka untuk memperhitungkan perbedaan pelanggan dan perubahan situasi.Menurut Kotler, Armstrong (dalam Jaya, 2018:5),strategi penetapan harga adadah:

1. Penetapan harga diskon dan potongan harga, yakni mengurangi harga untuk memberikan penghargaan kepada pelanggan yang memberikan tanggapan seperti membayar lebih awal atau mempromosikan produk.

2. Penetapan harga tersegmentasi, yaknimenyesuaikan harga untuk membuat perbedaan diantara produk, pelanggan maupun lokasi.

3. Penetapan harga psikologis, yaknimenyesuaikan harga untuk mempengaruhi secara psikologis.

4. Penetapan harga promosi, yaknisewaktu-waktu mengurangi harga untuk meningkatkan penjualan dalam jangka pendek.

5. Penetapan harga geografis, yaitumenyesuaikan harga untuk memperhitungkan lokasi geografis pelanggan.

6. Penetapan harga dinamis, yaitumenyesuaikan harga terus menerus untuk memenuhi karakteristik dan kebutuhan pelanggan individual dan situasi.

\section{Keputusan Pembelian}

Keputusan pembelian menurut Kotler dan Keller yang dialih bahasakan oleh Benyamin Molan, dkk. (2009:183) adalah Keputusan pembelian merupakan tahap dalam proses pengambilan keputusan pembelian dimana konsumen benar-benar membeli. Keputusan pembelian menurut Kanuk (dalam Tolisindo, 2017:18) adalah pemilihan dari dua atau lebih alternatif pilihan keputusan pembelian, artinya bahwa seseorang dapat membuat keputusan, haruslah tersedia beberapa alternatif pilihan

\section{KERANGKA ANALISIS}

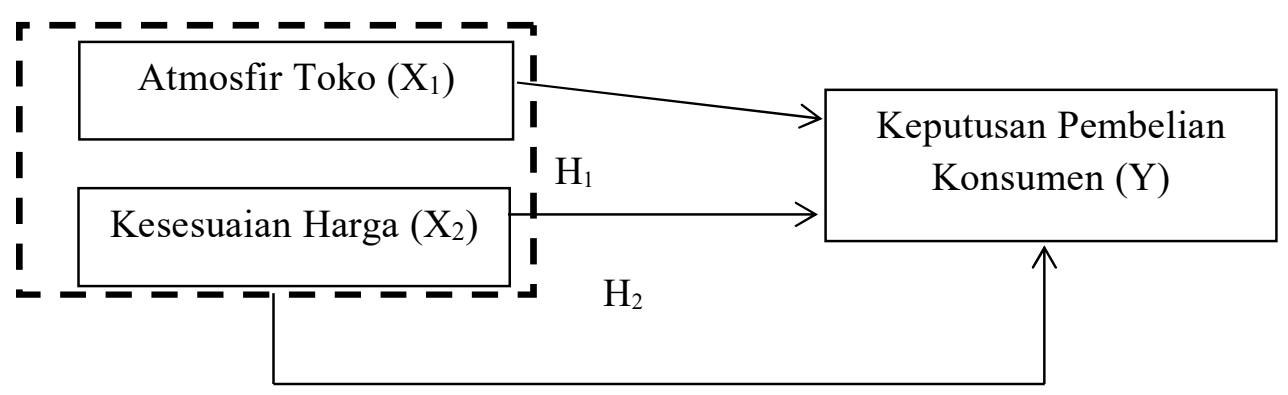

$\mathrm{H}_{3}$

Gambar1..Kerangka Analisis

\section{METODOLOGI}

\section{Jenis Penelitian dan Metode Pengumpulan Data}

Penelitian ini termasuk jenis penelitian deskriptif kualitatif.Deskriptif kualitatif adalah pengelolahn data menjadi sesuatu yang dapat diutarakan secara jelas dan tepat dengan tujuan agar dapat dimengerti oleh orang yang tidak langsung mengalaminya sendiri.Sugiyono (2012:35).

Dalam pengumpulan data, digunakan 2 metode penelitian yaitu penelitian lapangan (field research) dan ke perpustakaan (library research).

1. Penelitian lapangan

Untuk memperoleh data dan informasi dengan cara meninjau kembali secara langsung ke perusahaan, melalui:

a. Observasi

Merupakan metode penelitian dimana peneliti melakukan pengamatan secara langsung pada objek penelitian. 
b. Kuesioner

Merupakan metode pengumpulan data yang dilakukan dengan cara memberikan pertanyaan-pertanyaan kepada responden dengan panduan kuesioner.

2. Studi kepustakaan.

Merupakan metode pengumpulan data yang dilakukan dengan membaca buku-buku, literatur, jurnal-jurnal, referensi yang berkaitan dengan penelitian ini dan penelitian terdahulu yang berkaitan dengan penelitian yang sedang dilakukan.

\section{HASIL PENELITIAN DAN PEMBAHASAN}

\section{Uji Validitas Butir Pertanyan Variabel Atmosfir Toko}

Data hasil penelitian yang diperoleh dari 100 responden terlebih dahulu dilakukan uji validitas secara konstruks. Hasil uji validitas menggambarkan sah tidaknya instrumen dalam penelitian ini atau instrumen telah mengukur apa yang seharusnya diukur.

Uji validitas dalam penelitian ini dianalisis dengan mengkorelasi antara skor setiap butir pertanyaan dengan skor totalnya dari masing-masing variabel. Uji validitas ini dimaksudkan untuk memastikan seberapa baik suatu instrumen mengukur konsep yang seharusnya diukur.Instrumen yang valid berarti instrumen tersebut dapat digunakan untuk mengukur secara tepat dan benar.

Tabel 6. Uji Validitas Variabel Atmosfir $\left(\mathrm{X}_{1}\right)$

\begin{tabular}{|l|c|c|}
\hline \multicolumn{1}{|c|}{ Pertanyaan } & $\begin{array}{c}\text { Koofisien } \\
\text { Validitas 0,05 }\end{array}$ & Keterangan \\
\hline Exterior (bagian Luar Toko): & 0,524 & VALID \\
\hline Bangunan Toko Puncak Departemen Store Bengkulu cukup menarik & 0,722 & VALID \\
\hline Papan merk Toko Puncak Departemen Store Bengkulu terlihat jelas & 0,593 & VALID \\
\hline Desain Toko Puncak Departemen Store Bengkulu unik dan menarik & 0,731 & VALID \\
\hline Parkiran toko Puncak Departemen Store cukup strategis dan luas & 0,599 & VALID \\
\hline General Interior (bagian keseluruhan bagian toko): & 0,823 & VALID \\
\hline $\begin{array}{l}\text { Perabotan toko Puncak Departemen Store Bengkulu yang mendukung (panjang) } \\
\text { cukup menarik }\end{array}$ & 0,843 & VALID \\
\hline Perabotan toko sesuai dengan tema toko Puncak Departemen Store Bengkulu & \\
\hline $\begin{array}{l}\text { Pengaturan temperature udara dalam toko Puncak Departemen Store Bengkulu } \\
\text { cukup sejuk }\end{array}$ & 0,720 & VALID \\
\hline Store layout (tata letak): & 0,849 & VALID \\
\hline Meja pembayaran (kasir) cukup strategis & 0,834 & VALID \\
\hline Pengatura tata letak barang nyaman untuk konsumen lalu lalang & 0,634 & VALID \\
\hline Tata letak barang nyaman bagi konsumen & 0,787 & VALID \\
\hline Interior Display (pemajangan): & 0,728 & VALID \\
\hline Penciptaan display interior (tingkat kemenarikan) di dalam toko & & \\
\hline Penciptaan display interior di dalam yang rapi dan bersih & & \\
\hline Kerapian dalam menyusun produk-produk di dalam cukup manarik & & \\
\hline
\end{tabular}

Pengujian validitas instrumen masing-masing variabel dalam penelitian ini menggunakan sofware SPSS 17.00 for windows. Pengujian validitas yang digunakan adalah Korelasi Signifikansi Korelasi Pearson yang dipakai dalam penelitian ini adalah 0,05 . Apabila nilai signifikansinya lebih kecil dari 0,05 maka butir pertanyaan tersebut valid dan apabila nilai signifikansinya lebih besar dari 0,05 maka butir pertanyaan tersebut tidak valid Ghozali, (2016:156).Hasil uji validitas dari pengaruh atmosfer toko dan kesesuaian harga terhadapkeputusan pembelian secaralengkap dapat dilihat pada lampiran 3. Jadi validitas ingin mengukur apakah pertanyaan dalam kuesioner tersebut benar-benar dapat mengukur atau mewakili apa yang hendak kita ukur. Uji signifikansi dilakukan dengan cara membandingkan nilai $r$ hitung dengan $r$ tabel untuk degree of freedom $(d f)=n-2$ yaitu 100-2 $=98$, dalam hal ini $n$ adalah jumlah sampel. Maka nilai Koofisien validitas sebesar 0,05.

Untuk hasil uji validitas masing-masig masing-masing pertanyaan pada variabel atmosfir disetiap indikator dapat dilihat pada tabel 6. Berdasarkan tabel tersebut diatas, maka diperoleh hasil bahwa seluruh item pertanyaan untuk variabel atmosfir ( $\left.\mathrm{X}_{1}\right)$ adalah VALID, hal ini dibuktikan bahwa seluruh nilai korelasi pada tiap-tiap item pertanyaan lebih besar daripada 0,05.

\section{Uji Validitas Butir Pertanyan Variabel Kesesuaian Harga}

Untuk hasil uji validitas masing-masing pertanyaan pada variabel kesesuaian harga disetiap indikator dapat dilihat padatabel dibawah ini: 
Tabel 7. Uji Validitas Variabel Kesesuaian Harga(X2)

\begin{tabular}{|c|c|c|}
\hline Pertanyaan & Koofisien Validitas 0,05 & Keterangan \\
\hline \multicolumn{3}{|l|}{ Penetapan harga diskon (potongan harga): } \\
\hline Harga yang ditawarkan cukup terjangkau & 0,837 & VALID \\
\hline Harga diskon yang ditawarkan toko menarik bagi konsumen & 0,782 & VALID \\
\hline \multicolumn{3}{|l|}{ Penetapan harga tersegmentasi: } \\
\hline $\begin{array}{l}\text { Harga produk toko Puncak Departemen Store Bengkulu berbeda } \\
\text { dengan harga produk toko lain }\end{array}$ & 0,864 & VALID \\
\hline Pelanggan toko merasa puas dengan penetapan harga yang ditawarkan & 0,843 & VALID \\
\hline \multicolumn{3}{|l|}{ Penetapan harga psikologis: } \\
\hline Kualitas merk produk cukup menarik kosumen & 0,715 & VALID \\
\hline $\begin{array}{l}\text { Kualitas harga produk yang ditawarkan toko jangka waktunya tahan } \\
\text { lama }\end{array}$ & 0,812 & VALID \\
\hline \multicolumn{3}{|l|}{ Penetapan harga promosi: } \\
\hline $\begin{array}{l}\text { Penyampaian media promosi yang yang ditawarkan toko Puncak } \\
\text { Departemen Store Bengkulu mudah di pahami }\end{array}$ & 0,793 & VALID \\
\hline Promosi harga produk cukup menarik dan bervasiasi & 0,812 & VALID \\
\hline \multicolumn{3}{|l|}{ Penetapan harga geografis: } \\
\hline Lokasi toko Puncak Departemen Store Bengkulu strategis di pusat kota & 0,738 & VALID \\
\hline $\begin{array}{l}\text { Jarak tempuh toko Puncak Departemen Store Bengkulu mudah akses } \\
\text { jalannya }\end{array}$ & 0,829 & VALID \\
\hline \multicolumn{3}{|l|}{ Penetapan harga dinamis: } \\
\hline $\begin{array}{l}\text { Harga produk di toko Puncak Departemen Store Bengkulu cukup } \\
\text { terjangkau }\end{array}$ & 0,734 & VALID \\
\hline Harga produk cukup bervariasi dan ekonomis & 0,827 & VALID \\
\hline $\begin{array}{l}\text { Harga yang ada di toko Puncak Departemen Store Bengkulu cukup } \\
\text { dinamis dan konsisten }\end{array}$ & 0,791 & VALID \\
\hline
\end{tabular}

Sumber : Hasil Penelitian, 2019

Berdasarkan tabel 7 diatas maka diperoleh hasil bahwa seluruh item pertanyaan untuk variabel kesesuain harga $\left(\mathrm{X}_{2}\right)$ adalah VALID, hal ini dibuktikan bahwa seluruh nilai korelasi pada tiap-tiap item pertanyaan lebih besar daripada 0.05 .

\section{Uji Validitas Butir Pertanyan Keputusan Pembelian}

Untuk hasil uji validitasmasing-masing pertanyaan pada variabel kesesuaian harga disetiap indikator dapat dilihat pada tabel dibawah ini:

Tabel 8. Uji Validitas Variabel Keputusan Pembelian (Y)

\begin{tabular}{|c|c|c|}
\hline Pertanyaan & $\begin{array}{c}\text { Koofisien } \\
\text { Validitas } 0,05 \\
\end{array}$ & Keterangan \\
\hline \multicolumn{3}{|l|}{ Pembelian sepenuhnya terencana: } \\
\hline $\begin{array}{l}\text { Promosi produk baru di toko Puncak Departemen Store Bengkulu, selalu mendapat } \\
\text { potongan harga }\end{array}$ & 0,584 & VALID \\
\hline $\begin{array}{l}\text { Setiap membeli produk mahal, toko Puncak Departemen Store Bengkulu selalu } \\
\text { memberikan kupon berhadiah }\end{array}$ & 0,701 & VALID \\
\hline Produk yang ditawarkan selalu ada alternatif lain atau perbandingan dalam promosi & 0,783 & VALID \\
\hline $\begin{array}{l}\text { Kupon selalu disiapkan oleh toko Puncak Departemen Store Bengkulu dalam setiap } \\
\text { kali pembelian produk }\end{array}$ & 0,769 & VALID \\
\hline \multicolumn{3}{|l|}{ Pembelian sebagian yang direncanakan: } \\
\hline $\begin{array}{l}\text { Diskon produk yang dipajangan membuat menarik konsumen untuk membeli } \\
\text { meskipun menunda waktu }\end{array}$ & 0,619 & VALID \\
\hline $\begin{array}{l}\text { Merek dan kualitas produk yang didiskon selalu jadi pilihan konsumen meskipun } \\
\text { menunda waktu }\end{array}$ & 0,697 & VALID \\
\hline Produk pesanan selalu ada, meskipun waktunya ditunda 1 minggu & 0,767 & VALID \\
\hline Konsumen membutuhkan waktu lama untuk memilih produk yang berkualitas & 0,764 & VALID \\
\hline \multicolumn{3}{|l|}{ Pembelian terencana: } \\
\hline $\begin{array}{l}\text { Konsumen selalu memburu merk terkenal di toko Toko Puncak Departemen Store } \\
\text { Bengkulu }\end{array}$ & 0,753 & VALID \\
\hline $\begin{array}{l}\text { Katalog merk pakaian di Toko Puncak Departemen Store Bengkulu cukup berkualitas } \\
\text { dan menarik minat beli konsumen }\end{array}$ & 0,567 & VALID \\
\hline Pakaian yang dipajang sesuai dengan gambar di katalog & 0,758 & VALID \\
\hline Merk dan harga di katalog sesuai dengan harga di pajangan pada produk & 0,805 & VALID \\
\hline $\begin{array}{l}\text { Konsumen membuat catatan kecil untuk dibawa berbelanja ke Puncak Departement } \\
\text { Store }\end{array}$ & 0,762 & VALID \\
\hline
\end{tabular}

Sumber : Hasil Penelitian, 2019 
Berdasarkan tabel 8 diatas maka diperoleh hasil bahwa seluruh item pertanyaan untuk variabel keputusan pembelian (Y) adalah VALID, hal ini dibuktikan bahwa seluruh nilai korelasi pada tiap-tiap item pertanyaan lebih besar daripada 0,05 .

\section{Uji Realibilitas Butir Pertanyan Variabel Atmosfir dan Kesesuaian Harga Terhdap Keputusan}

Instrumen penelitian yang memenuhi kriteria valid selanjutnya dilakukan uji realiabilitas. Realibilitas merupakan ukuran suatu kestabilan dan konsistensi responden dalam menjawab hal yang berkaitan dengan butir pertanyaan. Pengujian reliabilitas isntrumen dalam penelitian ini menggunakan Reliabilitas instrumen dihitung dengan menggunakan rumus Cronbach's Alpha dengan bantuan program SPSS 17.00 for windows. Suatu variabel dikatakan reliabel jika memberikan nilai Cronbach Alpha $(\alpha)>0,05$. Adapun hasil perhitungan tingkat realibilitas setiap variabel dapat dilihat pada lampiran 3 .

Pertayaan yang telah di dinyatakan valid dalam uji validitas akan ditentukan realibilitasnya dengan kriteria sebagai berikut:

a. Jika $R_{\text {hitung }}>$ dari $R_{\text {tabel }}$ maka pernyataan reliabel

b. Jika $R_{\text {hitung }}<$ dari Rtabel maka pernyataan tidak reliabel

Setelah dihitung tingkat reliabilitas instrumen pada masing-masing butir pertanyaandengan menggunakan rumus Cronbach's Alphamaka hasil $\mathrm{R}_{\text {hitung }}$ dapat dilihat pada nilaiCronbach's Alphapada tabel dibawah ini :

Tabel 9. Realibilitas Variabel Atmosfit dan Kesesuaian Harga Terhadap Keputusan Pembelian

\begin{tabular}{|l|c|c|c|}
\hline \multicolumn{1}{|c|}{ Variabel } & Item & Nilai Cronbach's Alpha>0,5 & Keterangan \\
\hline Exterior & 4 & 0,525 & Handal \\
\hline Interior & 3 & 0,640 & Handal \\
\hline Layout & 3 & 0,724 & Handal \\
\hline Display & 3 & 0,529 & Handal \\
\hline Discount & 2 & 0,475 & Handal \\
\hline Tersegmentasi & 2 & 0,626 & Handal \\
\hline Psikologi & 2 & 0,291 & Handal \\
\hline Promosi & 2 & 0,448 & Handal \\
\hline Geografis & 2 & 0,571 & Handal \\
\hline Dinamis & 3 & 0,628 & Handal \\
\hline Sepenuhnya Terencana & 4 & 0,670 & Handal \\
\hline Sebagian Terencana & 4 & 0,676 & Handal \\
\hline Terencana & 5 & 0,772 & \\
\hline
\end{tabular}

Sumber: Output SPSS (hasil pengolahan data primer, 2019)

Berdasarkan tabel 9 diatas maka dapat diperoleh hasil bahwa seluruh item pertanyaan untuk adalah handal. Hal ini dibuktikan bahwa seluruh nilai Nilai Cronbach's Alphapada tiap-tiap item pertanyaan lebih besar daripada 0,5 .

\section{Analisis Regresi Linier Berganda}

Analisis regresi linear untuk lebih dari dua variabel disebut analisis regresi linear berganda Subagyo dan Djarwanto (2009:162).Hasil yang diperoleh dari pengolahan data dengan menggunakan program SPSS dan menggunakan persamaan regresi linear berganda dapat dilihat pada tabel dibawah ini;

Tabel 10 Hasil Pengujian Regresi Linear Berganda

\begin{tabular}{|l|r|r|r|r|r|}
\hline \multirow{2}{*}{ Model } & \multicolumn{2}{c|}{$\begin{array}{c}\text { Unstandardized } \\
\text { Coefficients }\end{array}$} & \multicolumn{1}{c|}{$\begin{array}{c}\text { Standardized } \\
\text { Coefficients }\end{array}$} & & \\
\cline { 2 - 5 } & \multicolumn{1}{c|}{$\mathrm{B}$} & Std. Error & Beta & \multicolumn{1}{c|}{$\mathrm{t}$} & \multicolumn{1}{c|}{ Sig. } \\
\hline 1 (Constant) & 11.178 & 3.661 & & 3.053 & .003 \\
X1 & .712 & .055 & .775 & 12.839 & .000 \\
X2 & .157 & .069 & .137 & 2.267 & .026 \\
\hline
\end{tabular}

a. Dependent Variable: KeputusanPembelian

Sumber: Output SPSS (hasil pengolahan data primer 2019

Analisis regresi linear berganda untuk lebih dari dua variabel disebut analisis regresi linear berganda Subagyo dan Djarwanto (2009:162). Data yang diperoleh lalu diolah dengan menggunakan 
program SPSS for Windows, dan menggunakan persamaan regresi linear berganda. Menurut Sugiyono (2014:277) persamaan regresi linier berganda yang ditetapkan sebagai berikut:

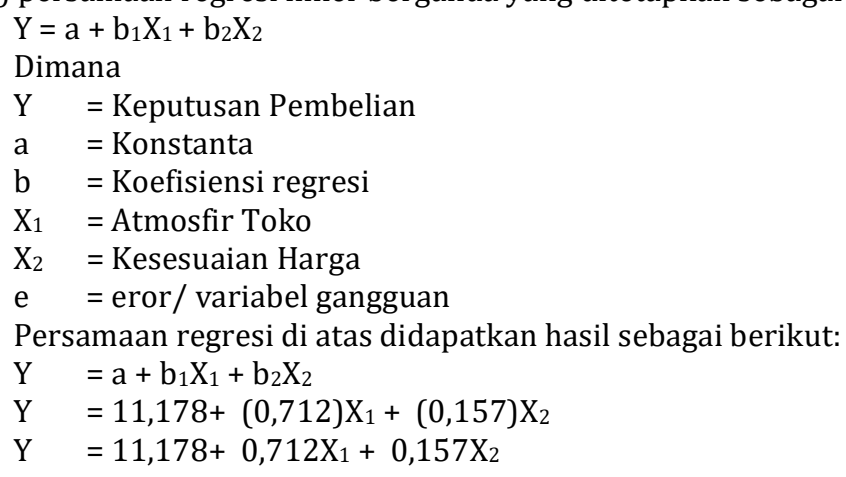

\section{Analisis Korelasi Ganda (R)}

Analisis ini digunakan untuk mengetahui hubungan antara dua atau lebih variabel independen (atmosfir dan kesesuaian harga) terhadap variabel dependen (keputusan pembelian) secara serentak. Koefisien ini menunjukkan seberapa besar hubungan yang terjadi antara variabel independen (atmosfir dan kesesuaian harga) secara serentak terhadap variabel dependen (keputusan pembelian). nilai $\mathrm{R}$ berkisar antara 0 sampai 1 , nilai semakin mendekati 1 berarti hubungan yang terjadi semakin kuat, sebaliknya nilai semakin mendekati 0 maka hubungan yang terjadi semakin lemah.Menurut Sugiyono (2010), adapun pedoman untuk memberikan interpretasi koefisien korelasi sebagai berikut:

$$
\begin{aligned}
& \begin{array}{lll}
0,00 & -0,199 & =
\end{array} \\
& \begin{array}{lll}
0,20 & -0,399 & =
\end{array} \\
& 0,40-0,599 \quad=\text { sedang } \\
& 0,60-0,799 \quad=\text { kuat } \\
& 0,80-1,000 \quad=\text { sangat kuat }
\end{aligned}
$$

Tabel 11 Hasil Analisis Korelasi Ganda (R)

\begin{tabular}{|l|c|r|r|r|}
\hline Model & \multicolumn{1}{|c|}{$\mathrm{R}$} & \multicolumn{1}{|c|}{ R Square } & \multicolumn{1}{|c|}{ Adjusted R Square } & \multicolumn{2}{c|}{$\begin{array}{c}\text { Std. Error of the } \\
\text { Estimate }\end{array}$} \\
\hline 1 & $.839 \mathrm{a}$ & .703 & .697 & 2.27627 \\
\hline
\end{tabular}

a. Predictors: (Constant), KesesuaianHarga, Atmosfir

Sumber: Output SPSS (hasil pengolahan data primer, 2019)

Berdasarkan tabel di atas diperoleh angka R sebesar 0,839. Hal ini menunjukkan bahwa terjadi hubungan yang sangat kuat antara atmosfir dan kesesuaian harga secara serentak terhadap keputusan pembelian.

\section{Analisis Determinasi $\left(\mathbf{R}^{2}\right)$}

Analisis determinasi dalam regresi linear berganda digunakan untuk mengetahui prosentase sumbangan pengaruh variabel independen (atmosfir dan kesesuaian harga) secara serentak terhadap variabel dependen (keputusan pembelian).Koefisien ini menunjukkan seberapa besar persentase variasi variabel independen yang digunakan dalam model mampu menjelaskan variasi variabel dependen. $\mathrm{R}^{2}$ sama dengan 0 , maka tidak ada sedikitpun prosentase sumbangan pengaruh yang diberikan variabel independen terhadap variabel dependen, atau variasi variabel independen yang digunakan dalam model tidak menjelaskan sedikitpun variasi variabel dependen. Sebaliknya $\mathrm{R}^{2}$ sama dengan 1 , maka prosentase sumbangan pengaruh yang diberikan variabel independen terhadap variabel dependen adalah sempurna, atau variasi variabel independen yang digunakan dalam model menjelaskan $100 \%$ variasi variabel dependen.

Berdasarkan tabel 11 di atas diperoleh angka $\mathrm{R}^{2}$ (R Square) sebesar 0,703 atau (70,3\%). Hal ini menunjukkan bahwa prosentase sumbangan pengaruh variabel independen (atmosfir dan kesesuaian harga) terhadap variabel dependen (perilaku konsumen) sebesar 70,3\%. Sedangkan sisanya sebesar $29,7 \% \%$ dipengaruhi atau dijelaskan oleh variabel lain yang tidak dimasukkan dalam model penelitian ini. Adjusted $R$ Square adalah nilai $\mathrm{R}$ Square yang telah disesuaikan, nilai ini selalu lebih kecil dari $\mathrm{R}$ Square dan angka ini bisa memiliki nilai negatif. Standard Error of the Estimate adalah suatu ukuran 
banyaknya kesalahan model regresi dalam memprediksikan nilai Y. Dari tabel 11 diatas dapat dilihat2.27627.ini berarti banyaknya kesalahan dalam prediksi keputusan pembelian sebesar 2.27627.Jika Standard error of the estimate kurang dari standar deviasi Y, maka model regresi semakin baik dalam memprediksi nilai Y.

\section{Uji Parsial (t)}

Uji statistik t bertujuanuntuk mengetahui apakah variable bebas atau variable independen (X) secara parsial(sendiri-sendiri) berpengaruh terhadap variabel terikatatau variable dependen (Y). Hasil output dari pengujian dengan mengunakan alat SPSS adalah sebagai berikut:

Tabel 12Hasil Uji Persial (t)

\begin{tabular}{|c|c|c|c|c|c|}
\hline \multirow[b]{2}{*}{ Model } & \multicolumn{2}{|c|}{ Unstandardized Coefficients } & \multirow{2}{*}{$\begin{array}{c}\text { Standardized } \\
\text { Coefficients } \\
\text { Beta }\end{array}$} & \multirow[b]{2}{*}{$\mathrm{t}$} & \multirow[b]{2}{*}{ Sig. } \\
\hline & B & Std. Error & & & \\
\hline $1 \quad$ (Constant) & 11.178 & 3.661 & & 3.053 & .003 \\
\hline Atmosfir & .712 & .055 & .775 & 12.839 & .000 \\
\hline KesesuaianHarga & .157 & .069 & .137 & 2.267 & .026 \\
\hline
\end{tabular}

a. Dependent Variable: Keputusan Pembelian

Sumber: Output SPSS (hasil pengolahan data primer 2019

Berdasarkan tabel output SPSS Coefficients diatas dapat diambil keputusan :

1. Uji t pada variabel atmosfirsebagai berikut:

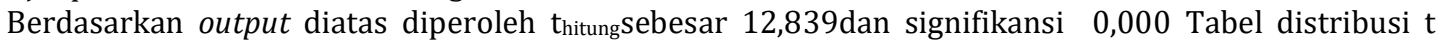
dicari pada $\mathrm{a}=5 \%$ dengan derajat kebebasan $/ \mathrm{df}=\mathrm{n} \quad \mathrm{k} \quad 1=100-2-1=97$ Maka tabel adalah sebesar 1,66. Maka dapat disimpulkan menerima Hipotesa artinyaterdapat pengaruh atmosfir terhadap keputusan pembelian pada konsumen yang berkunjung ke Puncak Departement Store Kota Bengkulu. Hal ini terlihat pada nilai ttabel $<$ thitungatau $1,66<12,839$.

2. Uji t pada variabel kesesuaian harga adalah sebagai berikut :

Berdasarkan output diatas diperoleh thitung sebesar 2,267 dan signifikansi 0,026. Tabel distribusi $t$ dicari pada $\mathrm{a}=5 \%$ dengan derajat kebebasan $/ \mathrm{df}=\mathrm{n} \quad \mathrm{k} \quad 1=100-2-1=97$ Maka tabel adalah sebesar 1,66. Maka dapat disimpulkan menerima hipotesa dikarenakan terdapat pengaruh kesesuaian hargaterhadap keputusan pembeliankonsumen yang berkunjung ke Puncak Departement Store Kota Bengkulu sebesar 2,267hal ini terlihat bahwathitung>ttabelatau2,267>1,66

Uji F

Uji ini digunakan untuk mengetahui apakah variabelindependen (atmosfir dan kesesuaian harga) secara bersama-sama berpengaruh secara signifikan terhadap variabel dependen (keputusan pembelian) Atau untuk mengetahui apakah model regresi dapat digunakan untuk memprediksi variabel berpengaruh/devenden atau tidak. Dari hasil output analisis regresi dapat diketahui nilai $\mathrm{F}$ dalam lampiran 3.

Uji f digunakan untuk mengetahui pengaruh semua variabel independen yang dimasukan dalam model regresi secara bersama-sama terhadap variable dependen yang di uji pada tingkat signifikansi 0,05. Dimana nilai $F_{\text {tabel }}$ (lihat lampiran distribusi f untuk probabilitas 0,05) adalah sebesar 3,09. Adapun hipotesis (dugaan) yang diajukan dalam uji $\mathrm{F}$ ini adalah ada pengaruh positif antara atmosfir dan kesesuaian harga terhadap keputusan pembelian pada konsumen yang berkunjung kePuncak Departement StoreKota Bengkulu.

Hasil uji koefisien signifikansi simultan (uji statistik F) dapat dilihat pada tabel Coefficients ${ }^{\mathrm{a}}$ ANOVA ${ }^{\mathrm{b}}$ dibawah ini :

Tabel 13. Hasil Pengujian Simultan (F)

\begin{tabular}{|l|r|r|r|r|c|}
\hline Model & Sum of Squares & df & Mean Square & F & Sig. \\
\hline 1 Regression & 1191.644 & 2 & 595.822 & 114.992 & $.000^{\mathrm{a}}$ \\
Residual & 502.596 & 97 & 5.181 & & \\
Total & 1694.240 & 99 & & & \\
\hline
\end{tabular}

a. Predictors: (Constant), KesesuaianHarga, Atmosfir

b. Dependent Variable: KeputusanPembelian

Sumber: Output SPSS (hasil pengolahan data primer, 2019) 
Berdasarkan perbandingan nilai Fhitung dengan $F_{\text {tabel }}$ maka nilai $F_{\text {hitung }}$ lebih besar daripada nilai Ftabel yaitu 114,992> 3,09 maka disimpulkan bahwa hipotesis diterima, artinya setelah dilakukan pengujian secara serentak maka ada pengaruh positif antara atmosfir dan kesesuaian harga terhadap keputusan pembelian diPuncak Departement StoreKota Bengkulu.

\section{Pembahasan}

Keputusan pembelian menurut Kotler dan Keller yang dialih bahasakan oleh Benyamin Molan, dkk. (2009:183) adalah Keputusan pembelian merupakan tahap dalam proses pengambilan keputusan pembelian dimana konsumen benar-benar membeli. Handy Surya Jaya (2018) mengatakan bahwa terdapat pengaruh atmosfir toko pada indikator kebersihan dan kesesuaian harga dengan kualitas produk terhadap keputusan pembelian dikarenakan terbukti dapat membuat konsumen puas berbelanja dan melakukan pembelian ulang pada Temday Store.

Penelitian ini sejalan dengan teori yang dikemukakan oleh Kotler dan Keller juga penelitian yang dilakukan oleh Handy Surya Jaya bahwa terdapat hubungan yang kuat antara atmosfir dan kesesuaian harga terhadap keputusan pembelian pada Puncak Departement Store Kota Bengkulu.Hal ini dapat dilihat pada tabel berikut ini:

Tabel 14. Hasil Anlisis Regresi Berganda Pada Variabel Atmosfir ( $\left.\mathrm{X}_{1}\right)$ dan Kesesuaian Harga $\left(\mathrm{X}_{2}\right)$ Terhadap Keputusan Pembelian (Y)

\begin{tabular}{|l|l|c|c|c|c|}
\hline No & Variabel Indevenden & Koefisien B & $\begin{array}{c}\text { Nilai Sig. Uji F } \\
\text { jik }<0,05\end{array}$ & $\begin{array}{c}\text { Nilai Sig. Uji t } \\
\text { Jika }<0,05\end{array}$ & $\begin{array}{c}\text { Uji R Dan } \\
\text { Uji R } \mathrm{R}^{2}>0,309\end{array}$ \\
\hline 1 & Keputusan Pembelian & 0,819 & & 0,003 & \\
\hline & Atmosfir & 0,712 & & 0,000 & \\
\hline & Keseuaian Harga & 0,157 & & 0,026 & \\
\hline 2 & Uji F & & 0,000 & & \\
\hline 3 & Uji R & & & & 0,839 \\
\hline 4 & Uji R Square & & & & 0,703 \\
\hline
\end{tabular}

Sumber : Hasil penelitian, Diolah 2019

Dari tabel diatas dapat dijelaskan bahwa nilai koefisien beta (B) sebesar 11,178yang artinya apabila tidak ada variabl atmosfir dan kesesuaian maka keputusan pembelian senilai11,178, Koefisien regresi variabel atmosfir $\left(\mathrm{X}_{1}\right)$ sebesar 0,712 artinya jika keesuaian harga nilainya tetap dan atmosfir naik 1 maka keputusan pembelian akan mengalami kenaikan sebesar 0,712. Koefisien bernilai positif artinya terjadi hubungan positif antara atmosfir terhadap keputusan pembelian, semakin tinggi/bagus atmosfir toko maka semakin tinggi keputusan pembelian.

Nilai koefisien kesesuaian hrga $\left(\mathrm{X}_{2}\right)$ sebesar 0,157 artinya jika variabel independen lain (atmosfir) nilainya tetap dan kesesuaian harga mengalami kenailan $1 \%$ maka keeputusan pembelian $(\mathrm{Y})$ akan mengalami kenaikan sebesar 0,157 . Koefisien bernilai positif artinya terjadi hubungan positif antara kesesuaian harga terhadap keputusan pembelian, semakin bagus kesesuaian harga maka semakin besar peluang konsumen dalam memutuskan untuk membeli/berbelanja.

Berdasarkan tabel di atas diperoleh angka $\mathrm{R}^{2}$ (R Square) sebesar 0,703 prosentase sumbangan pengaruh variabel independen (atmosfit dan kesesuaian harga) terhadap variabel dependen (perilaku konsumen) sebesar 70,3\%. Sedangkan sisanya sebesar $29,7 \%$ dipengaruhi atau dijelaskan oleh variabel lain yang tidak dimasukkan dalam model penelitian ini.

Berdasarkan perbandingan nilai $\mathrm{F}_{\text {hitung }}$ dengan $\mathrm{F}_{\text {tabel }}$ maka nilai Fhitung lebih besar daripada nilai Ftabelyaitu 114,992 > 3,09 maka disimpulkan bahwa hipotesis diterima, artinya setelah dilakukan pengujian secara serentak maka ada pengaruh positif antara atmosfir dan kesesuaian harga terhadap keputusan pembelian diPuncak Departement StoreKota Bengkulu.

\section{KESIMPULAN}

1. Dari persamaan regresi linier berganda, $Y=11,178+0,712 X_{1}+0,157 X_{2}$ dimana $Y$ adalah keputusan pembelian maka nialai koefisien beta (B) sebesar 11,178yang artinya apabila tidak ada variabel atmosfir dan kesesuaian maka keputusan pembelian adalah sebesar11,178.Koefisien regresi variabel atmosfir $\left(\mathrm{X}_{1}\right)$ sebesar 0,712 artinya jika keesuaian harga nilainya tetap dan atmosfir naik 1 maka keputusan pembelian akan mengalami kenaikan sebesar 0,712. Koefisien bernilai positif artinya terjadi hubungan positif antara atmosfir terhadap keputusan pembelian, semakin tinggi/ bagus atmosfir toko maka semakin tinggi keputusan pembelian.Nilai koefisien kesesuaian hrga $\left(\mathrm{X}_{2}\right)$ 
sebesar 0,157 artinya jika variabel independen lain (atmosfir) nilainya tetap dan kesesuaian harga mengalami kenailan 1\% maka keeputusan pembelian (Y) akan mengalami kenaikan sebesar 0,157. Koefisien bernilai positif artinya terjadi hubungan positif antara kesesuaian harga terhadap keputusan pembelian, semakin bagus kesesuaian harga maka semakin besar peluang konsumen dalam memutuskan untuk membeli/berbelanja.

2. Uji t pada variabel atmosfir diperolehthitungsebesar 12,839 dan signifikansi 0,000 Tabel distribusi $t$ dicari pada $\mathrm{a}=5 \%$ dengan derajat kebebasan $/ \mathrm{df}=\mathrm{n} \quad \mathrm{k} \quad 1=100-2-1=97$ Maka tabel adalah sebesar 1,66. Maka dapat disimpulkan menerima Hipotesa artinyaterdapat pengaruh atmosfir terhadap keputusan pembelian pada konsumen yang berkunjung ke Puncak Departement Store Kota Bengkulu. Hal ini terlihat pada nilai tabel $<$ thitungatau $1,66<12,839$.

3. Uji t pada variabel kesesuaian harga diperoleh $t_{\text {hitung }}$ sebesar 2,267 dan signifikansi 0,026. Tabel distribusi $\mathrm{t}$ dicari pada $\mathrm{a}=5 \%$ dengan derajat kebebasan $/ \mathrm{df}=\mathrm{n} \quad \mathrm{k} \quad 1=100-2-1=97$ Maka tabel adalah sebesar 1,66. Maka dapat disimpulkan menerima hipotesa dikarenakan terdapat pengaruh kesesuaian hargaterhadap keputusan pembeliankonsumen yang berkunjung ke Puncak Departement Store Kota Bengkulu sebesar 2,267hal ini terlihat bahwathitung>ttabelatau2,2671> 1,66.

4. Nilai $\mathrm{R}^{2}$ (R Square) sebesar 0,703 ini artinya prosentase sumbangan pengaruh variabel independen (atmosfit dan kesesuaian harga) terhadap variabel dependen (perilaku konsumen) sebesar 70,3\%. Sedangkan sisanya sebesar 29,7\% \% dipengaruhi atau dijelaskan oleh variabel lain yang tidak dimasukkan dalam model penelitian ini.

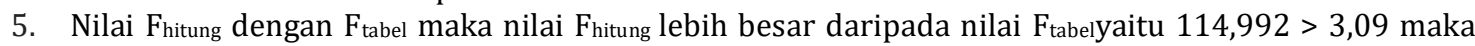
disimpulkan bahwa hipotesis diterima, artinya setelah dilakukan pengujian secara serentak maka ada pengaruh positif antara atmosfir dan kesesuaian harga terhadap keputusan pembelian diPuncak Departement StoreKota Bengkulu.

\section{SARAN}

1. Dalam mempengaruhi keputusan pembelian diPuncak Departement StoreKota Bengkulu agar mau berbelanja maka pihak perusahaan perlu mempertahankan kesesuaian harga. Dikarenakan dalam hasil penelitian ini bahwa kesesuaian harga berpengaruh terhadap keputusan pembelian.

2. Hasil penelitian ini bisa dijadikan masukan dalam menentukan kebijakan penyusunan strategi dalam meningkatkan penjualan.

3. Penelitian lain diharapkan mencari variabel independen lainnya yang mempengaruhi keputusan pembelian, karena keputusan pembelian bukan hanya dipengaruhi oleh atmosfir dan kesesuaian harga, mungkin bisabisa dipengaruhi oleh promosi, pelayanan dan lain-lain.

\section{DAFTAR PUSTAKA}

Amstrong, Gary \& Philip, Kotler.(2012) Dasar-Dasar Pemasaran. Jilid I, Erlangga: Jakarta. Arikunto, S. 2010. Prosedur Penelitian Suatu Pendekatan Praktik. Jakarta. Rineka Cipta. Assauri. 2013. Manajemen Pemasaran. Jakarta. Rajawali Pers.

Ally, Mohamed. 2009. Mobile Learning Transforming the Delivery of Education and. Training. Canada. AU Press. Athabasca University. Penerjemah: Benyamin Molan, dkk.

Berman dan Evans. 2010. Retail Management. 12 th. Jakarta.Edition.

Bentar Prastyan. 2014. Pengaruh Variabel-Variabel Atmosfir Toko Terhadap Minat Beli Konsumen Pada Swalayan Toko Baru Wonogiri Kota tahun 2014. Fakultas ekonomi.Universitas Muhammadiyah Surakarta.

Ghozali, Imam. 2011. Aplikasi Analisis Multivariate Dengan Program SPSS. Semarang. Badan Penerbit Universitas Diponegoro.

Kotler dan Armstrong, 2018.Prinsip-Prinsip Pemasaran.Edisi. 13. Jilid 1. Jakarta: Erlangga.

Kotler \& Keller. 2012. Manajemen Pemasaran. Jilid I Edisi ke 12. Jakarta. Erlangga.

Karmela dan Junaedi, Fajar.2009.Komunikasi Massa Pengantar Teoritis.Yogyakarta.Santusta.

Levy \& Weitz. 2009. Retailing Management, 7 th edition, Boston: McGraw Hill-Irwin.

Sutisna.2012.Perilaku Konsumen dan Komunikasi Pemasaran.Edisis kedua, Bandung. Remaja Rosdakarya. Subagyo dan Djarwanto 2009.Statistik Induktif.Edisi keempat.Yogyakarta.BPFE.

Swastha, Basu dan Sukotjo, Ibnu. 2007. Pengantar Bisnis Modern. edisi 3. Yogyakarta. Liberty.

Schiffman dan Kanuk. 2008. Perilaku Konsumen. Edisi ke 7. Jakarta. Indeks.

Sugiyono.2012. Metode Penelitian Kuantitatif Kualitatif dan R\&D. Bandung.Alfabeta. 